\title{
Prospective, randomized multicenter study of cervical arthroplasty versus anterior cervical discectomy and fusion: 5-year results with a metal-on-metal artificial disc
}

\author{
Domagoj Coric, MD, ${ }^{1}$ Richard D. Guyer, MD, ${ }^{2}$ Pierce D. Nunley, MD, ${ }^{3}$ David Musante, MD, ${ }^{4}$ \\ Cameron Carmody, MD, ${ }^{5}$ Charles Gordon, MD, ${ }^{6}$ Carl Lauryssen, MD, ${ }^{7}$ Margaret O. Boltes, RN, ${ }^{1}$ and \\ Donna D. Ohnmeiss, DrMed ${ }^{8}$
}

${ }^{1}$ Carolina Neurosurgery and Spine Associates, Charlotte; ${ }^{4}$ Triangle Orthopedics Associates, Durham, North Carolina; ${ }^{3}$ Spine
Institute of Louisiana, Shreveport, Louisiana; ${ }^{5}$ Plano Orthopedic Sports Medicine and Spine Center, Plano; ${ }^{6}$ Gordon Spine
Associates, Tyler; ${ }^{7}$ NeuroTexas, Austin; ${ }^{2}$ Texas Back Institute; and ${ }^{8}$ Texas Back Institute Research Foundation, Plano, Texas

OBJECTIVE Seven cervical total disc replacement (TDR) devices have received FDA approval since 2006. These devices represent a heterogeneous assortment of implants made from various biomaterials with different biomechanical properties. The majority of these devices are composed of metallic endplates with a polymer core. In this prospective, randomized multicenter study, the authors evaluate the safety and efficacy of a metal-on-metal (MoM) TDR (Kineflex|C) versus anterior cervical discectomy and fusion (ACDF) in the treatment of single-level spondylosis with radiculopathy through a long-term (5-year) follow-up.

METHODS An FDA-regulated investigational device exemption (IDE) pivotal trial was conducted at 21 centers across the United States. Standard validated outcome measures including the Neck Disability Index (NDI) and visual analog scale (VAS) for assessing pain were used. Patients were randomized to undergo TDR using the Kineflex|C cervical artificial disc or anterior cervical fusion using structural allograft and an anterior plate. Patients were evaluated preoperatively and at 6 weeks and 3, 6, 12,24, 36, 48, and 60 months after surgery. Serum ion analysis was performed on a subset of patients randomized to receive the MoM TDR.

RESULTS A total of 269 patients were enrolled and randomly assigned to undergo either TDR (136 patients) or ACDF (133 patients). There were no significant differences between the TDR and ACDF groups in terms of operative time, blood loss, or length of hospital stay. In both groups, the mean NDI scores improved significantly by 6 weeks after surgery and remained significantly improved throughout the 60 -month follow-up (both $p<0.01$ ). Similarly, VAS pain scores improved significantly by 6 weeks and remained significantly improved through the 60 -month follow-up (both $p<0.01$ ). There were no significant changes in outcomes between the 24- and 60-month follow-ups in either group. Range of motion in the TDR group decreased at 3 months but was significantly greater than the preoperative mean value at the 12and 24-month follow-ups and remained significantly improved through the 60-month period. There were no significant differences between the 2 groups in terms of reoperation/revision surgery or device-/surgery-related adverse events. The serum ion analysis revealed cobalt and chromium levels significantly lower than the levels that merit monitoring.

CONCLUSIONS Cervical TDR with an MoM device is safe and efficacious at the 5-year follow-up. These results from a prospective randomized study support that Kineflex|C TDR as a viable alternative to ACDF in appropriately selected patients with cervical radiculopathy.

Clinical trial registration no.: NCT00374413 (clinicaltrials.gov)

https://thejns.org/doi/abs/10.3171/2017.5.SPINE16824

KEY WORDS total disc replacement; cervical spine; artificial disc; Kineflex|C; anterior cervical fusion; anterior plate; FDA trial; prospective study; randomized study

\footnotetext{
ABBREVIATIONS $\mathrm{ACDF}=$ anterior cervical discectomy and fusion; $\mathrm{ASD}=$ adjacent-segment degeneration; $\mathrm{HO}=$ heterotopic ossification; IDE = investigational device exemption; MoM = metal on metal; NDI = Neck Disability Index; ROM = range of motion; TDR = total disc replacement; VAS = visual analog scale.

SUBMITTED July 18, 2016. ACCEPTED May 23, 2017.

INCLUDE WHEN CITING Published online January 5, 2018; DOI: 10.3171/2017.5.SPINE16824.
} 
$\mathrm{S}$ EVEN cervical total disc replacement (TDR) devices have received FDA approval since 2006. Although cervical artificial disc types are often conceptualized as a single type of device, they are actually a diverse group of implants with different designs, materials, and biomechanical properties. The first TDR device to receive FDA approval was the Prestige ST (Medtronic Sofamor Danek), a metal-on-metal (MoM) device made from stainless steel. ${ }^{21}$ A later version with a low profile modification of the original design (Prestige LP) was made from a titanium ceramic composite and received FDA approval in 2014. 7 The other 5 FDA-approved devices are all metal (cobalt-chrome or titanium alloy) on polymer (polyethylene or polyurethane). ${ }^{10,11,22,24,28}$ Other devices are in various states of investigational trials. Currently, a follow-up of 2-5 years is available from some of the FDA trials comparing the metal and polymer disc designs to anterior cervical discectomy and fusion (ACDF). The study findings have consistently showed both TDR and ACDF to result in significant improvement by 6 weeks to 3 months after surgery with improvement maintained throughout the follow-up period. ${ }^{4,10,12,24,25,28,31}$ Total disc replacement was found to produce noninferior results in all the studies and even superior results on some measures. Total disc replacement outcomes similar to those of the FDA-regulated trials have been reported from other countries as well., ${ }^{1,26,27,30}$ There have been no prospective randomized reports of a cobalt-chromium MoM cervical TDR device with a long-term follow-up. The MoM devices have been the least studied and, because of problems associated with MoM hip prostheses, 5,17 the most controversial. The theoretical benefit of MoM devices is durability. This is especially relevant in cervical arthroplasty for which the patient population is generally younger, as compared with total joint replacement patients, and the devices are expected to last for several decades. The central concern related to MoM TDR devices relates to wear debris, including the potential risks of pseudotumor formation and osteolysis. ${ }^{2,9,13}$ The purpose of the current prospective randomized study was to evaluate the safety and efficacy of MoM TDR compared with ACDF in the treatment of single-level spondylosis with radiculopathy through a 5-year follow-up. In a subset of patients, serum ion analysis was performed to investigate wear debris.

\section{Methods}

Patients with symptomatic, single-level, cervical disc disease from C-3 to C-7 with radiculopathy were randomized using a 1:1 ratio at 21 institutions as part of an FDA-regulated investigational device exemption (IDE) pivotal trial to undergo either ACDF with a standardized corticocancellous allograft and anterior screw/plate fixation or KineflexIC artificial disc placement. A total of 269 patients were enrolled with 136 patients undergoing TDR and 133 patients assigned to ACDF. Selection criteria as well as a detailed description of the study population have been published elsewhere. ${ }^{3}$ Primary inclusion criteria were the failure of at least 6 months of nonoperative care or progressive symptoms, signs of nerve root compression, and a score of at least 40 on the Neck Disability Index (NDI). Exclusion criteria included severe facet degeneration, bridging osteophytes, prior cervical fusion, or severe myelopathy $(<3 / 5$ muscle strength). Institutional review board approval was obtained at all 21 institutions, and all patients provided informed consent prior to study participation. This study was registered with the ClinicalTrials. gov database (http://clinicaltrials.gov), and its registration no. is NCT00374413.

Patients were evaluated preoperatively and at 6 weeks and $3,6,12,24,36,48$, and 60 months postoperatively. Evaluations included neurological examination (motor strength, sensory function, and reflexes), radiography (anteroposterior, neutral lateral, flexion, and extension views), adverse event monitoring, and patient-completed questionnaires. Pain and function were assessed using validated outcome measures including the NDI and a visual analog scale (VAS) assessing pain. The patients completed these outcome measures without assistance.

Overall success was a composite end point that required the satisfaction of 4 criteria: 1) improvement of at least $20 \%$ in the NDI score at 60 months compared with baseline; 2) no device failures (defined as breakage, migration, or mechanical failure of the components); 3 ) no supplemental index surgery (defined as no index-level revision, removal, supplemental fixation, or device-related reoperation); and 4) no major device-related adverse event (which included nonunion in the ACDF group). In addition, at the request of the FDA, an analysis of an alternative definition of overall success was applied to the data following completion of the study. This alternate primary end point required the satisfaction of 5 criteria for success: 1) 15-point improvement in the NDI score at 60 months from the baseline score; 2) no device failures (defined as breakage, migration, or mechanical failure of the components); 3) no supplemental index surgery failure (defined as no index-level revision, removal, supplemental fixation, or device-related reoperation); 4) no major device-related adverse event (which included nonunion in the ACDF group); and 5) maintenance or improvement of neurological status at 24 months postoperatively.

Reoperation and revision surgery data were collected. These were essentially defined as any subsequent surgical intervention at the index level. Adverse events were reviewed and classified by a Clinical Events Committee independent of the study. We report those events occurring through the 5-year follow-up that were classified as definitely, probably, or possibly related to the device or in relation to the surgical procedure. Each patient was represented once in the reporting and according to the most severe category; for example, if a patient had an adverse event classified as definitely device related and also as probably surgery related, he or she would be reported in the results section as definitely device related.

An independent core lab (Medical Metrics) analyzed radiographs for range of motion (ROM) implant migration, subsidence, and radiolucency (any discernable gap between the implant and vertebral body endplates) around the implants, heterotopic ossification (HO), and adjacentsegment degeneration (ASD). Heterotopic ossification was 
TABLE 1. Heterotopic ossification scoring

\begin{tabular}{ccc}
\hline $\begin{array}{c}\text { Grade in } \\
\text { Current Study }\end{array}$ & Description & $\begin{array}{c}\text { Mapping to } \\
\text { McAfee Class }^{*}\end{array}$ \\
\hline 0 & None: no evidence of osteophyte formation or HO & 0 \\
\hline 1 & Mild: isolated points of initial hyperostosis or islands of bone in soft tissue & I \\
\hline 2 & $\begin{array}{c}\text { Moderate: bone does not occur w/in the disc space (planes formed by 2 adjacent endplates); bony protru- } \\
\text { sions project more or less horizontally from vertebral bodies }\end{array}$ & $\begin{array}{c}\text { Severe: bone occurs btwn 2 planes formed by vertebral endplates but does not bridge; osteophytes curve in } \\
\text { direction of intervertebral disc \& may come into contact w/ osteophytes on adjacent vertebrae }\end{array}$ \\
\hline 3 & $\begin{array}{c}\text { Bridging: an apparent continuous connection of bridging bone exists btwn adjacent endplates; osteophytes } \\
\text { of adjacent vertebrae appear fused, thereby forming a bridge across intervening joint }\end{array}$ & IV \\
\hline 4 &
\end{tabular}

* McAfee et al., 2003.

qualitatively assessed based on the formation of osteophytes and/or ectopic bony formation (Table 1); the scoring was adapted from the McAfee scale ${ }^{18}$ to place greater emphasis on earlier stages of ossification. Adjacent segment degeneration was assessed on a scale ranging from 0 to 3 , indicating none, mild $(<33 \%$ disc space narrowing, mild osteophytes, no endplate sclerosis), moderate (33\%$66 \%$ disc space narrowing, moderate osteophytes, mild to moderate endplate sclerosis), or severe ( $>66 \%$ disc space narrowing, severe osteophytes, at least moderate endplate sclerosis). In the ACDF group, fusion was defined using a composite measure consisting of 1) bridging trabecular
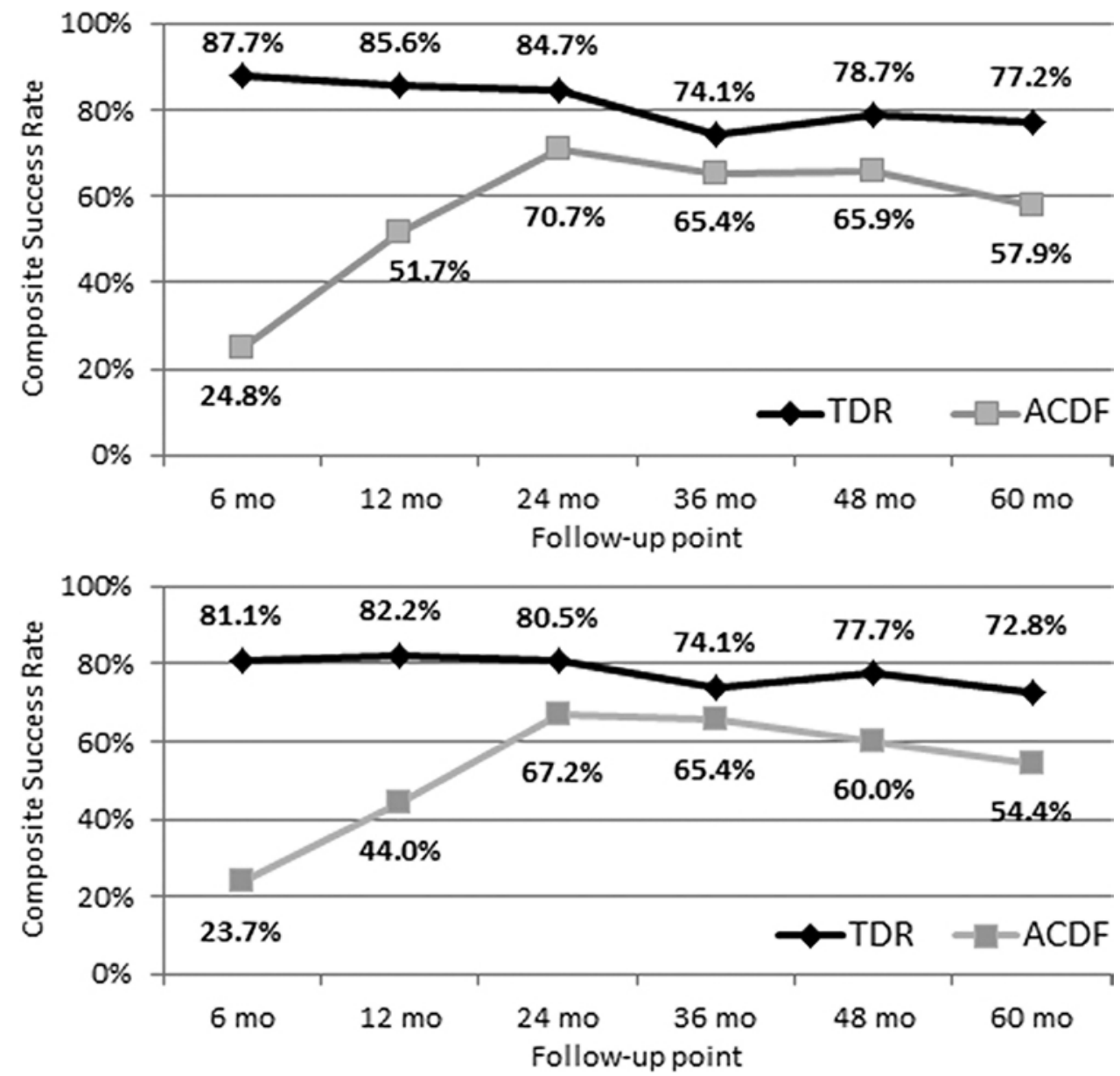

FIG. 1. Upper: Percentage of patients meeting the composite 4-item success criteria at follow-up. At all points but the 36-and 48-month follow-ups, the values were significantly greater for the TDR group $(p<0.05)$ than for the ACDF group. Lower: Based on the alternate 5 -item criteria, the success rate in the TDR group was significantly greater at all but the 36-month time point. 


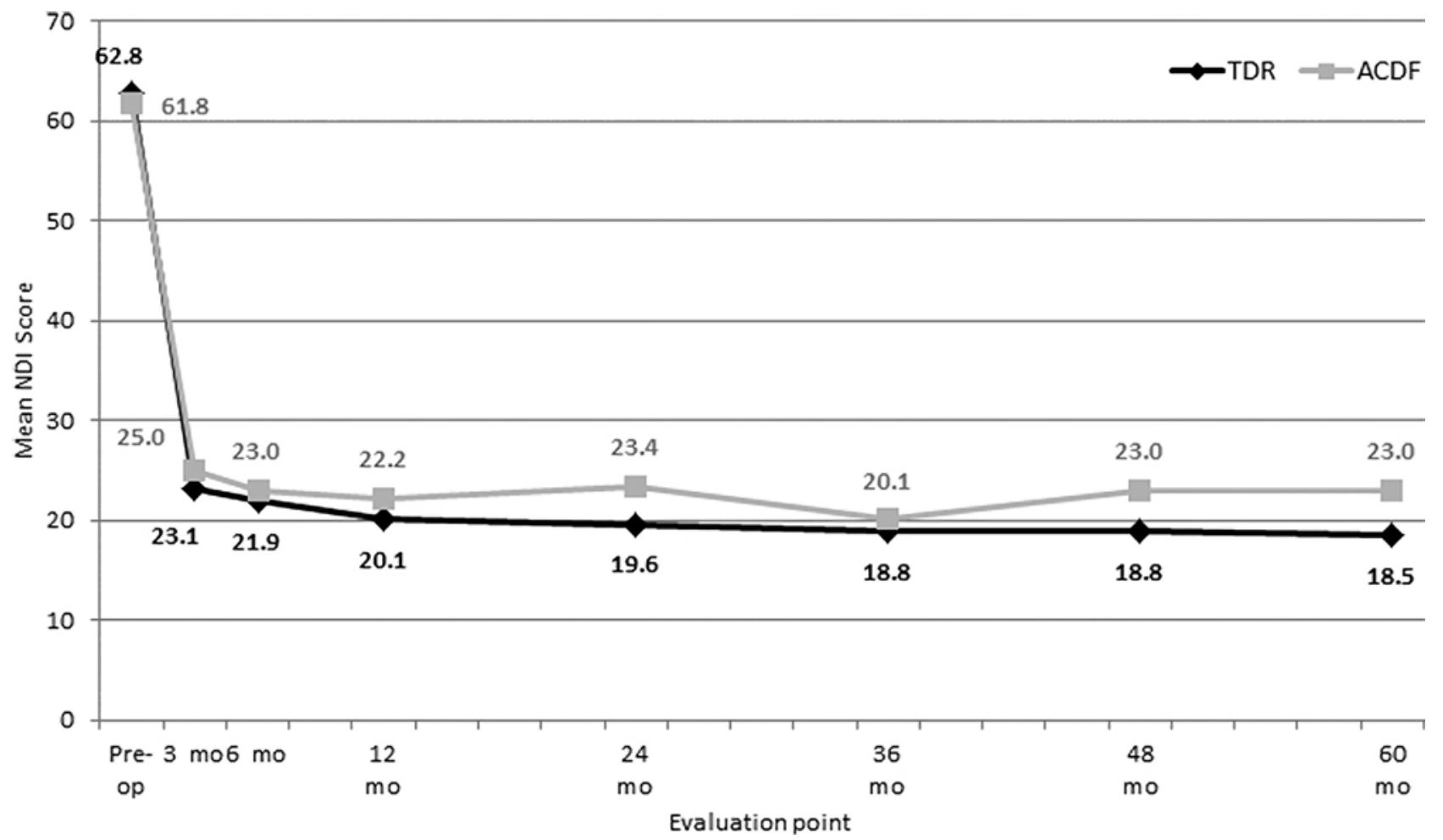

FIG. 2. The mean NDI scores improved significantly in the TDR and ACDF groups by 6 weeks after surgery and remained significantly improved throughout the follow-up.

bone, 2) angular motion $\left.<5^{\circ}, 3\right)$ translational motion $<3$ $\mathrm{mm}$, and 4$)<50 \%$ radiolucency along the bone-implant interface.

Investigators were instructed to have patients in both groups wear cervical collars until soft tissue healing had occurred. The use of nonsteroidal antiinflammatory agents was not mandatory in either group.

\section{Serum Ion Analysis}

Serum ion analysis was prospectively performed according to a prespecified protocol. Blood samples were taken before surgery and during follow-up visits and were collected from 27 patients. The patients were from multiple sites, but the number of sites participating in the serum ion evaluation was limited given the availability of facilities to appropriately handle the serum. No power analysis was performed on this cohort as it was intended to represent a simple sampling of study patients. Blood samples were collected and handled based on the protocol from the Rush University Medical Center University Medical Center Trace Metal Analysis Laboratory where the analyses were performed. Three vials of blood were collected at each visit, one to rinse the system and the other two for analysis. The blood was allowed to clot, and the sample was processed in a centrifuge to separate the serum. Samples were shipped packed in dry ice and were stored frozen until analyzed. Cobalt and chromium levels were assayed using high-resolution inductively coupled plasma mass spectrometry. To place values from the current study into context, they were compared with values suggested to warrant monitoring in hip replacement patients as published by the Medicines and Healthcare products Regulatory Agency ${ }^{19}$ and another published value. $^{29}$

\section{Statistical Design and Analysis}

The study protocol specified a 1:1 randomization to investigational and control groups, and patients were not made aware of their randomization until after their surgical procedure. The primary efficacy analysis comparing TDR to ACDF was completed using Blackwelder's test. The study was statistically powered and assumed an $80 \%$ desired power for a $10 \%$ delta as the noninferiority margin. Two-sided 90\% CI and 95\% CI for the difference in response rates were shown as derived from the normal approximation to the binomial. The $\mathrm{p}$ value for Blackwelder's test for noninferiority is also presented for the noninferiority margin of $10.0 \%$ (0.1 in difference in proportions). Fisher's exact test was used to compare the composite success rate at the follow-up points. A $p$ value $<0.05$ was statistically significant.

\section{Results}

At 60 months, data were available for $68.4 \%$ of the TDR group and $62.4 \%$ of the ACDF group.

\section{Overall Clinical Success}

At the 60-month follow-up, the composite clinical success rate based on the 4 -item success criteria was signifi- 


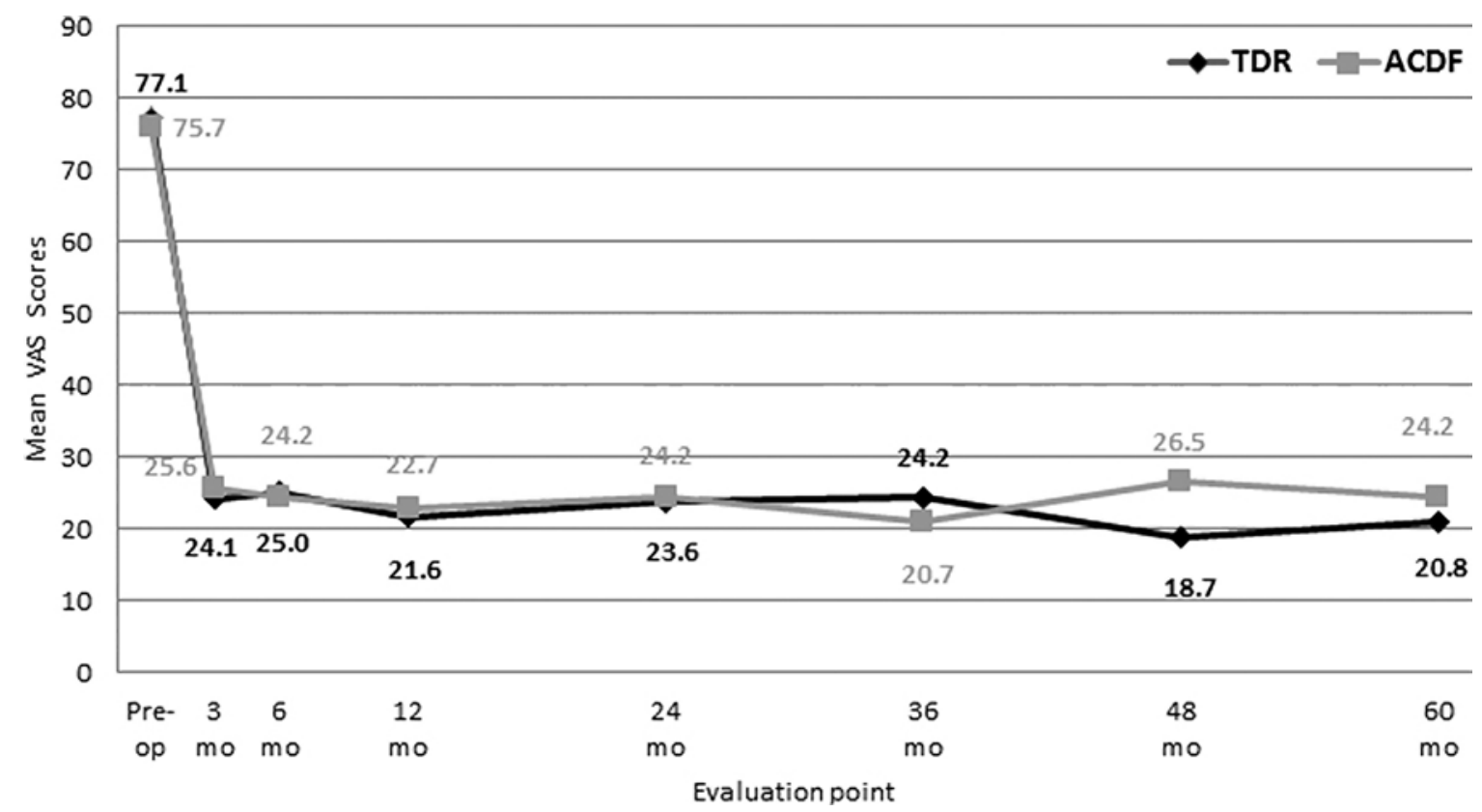

FIG. 3. The mean VAS pain scores improved significantly in the TDR and ACDF groups by 6 weeks after surgery and remained significantly improved throughout the 5-year follow-up.

cantly higher in the TDR group than in the ACDF group (77.2\% vs 57.9\%, p < 0.05; Fig. 1 upper). At no point was the TDR success rate lower than that in the fusion group. Only at the 36-month $(\mathrm{p}>0.20)$ and 48 -month $(0.05<\mathrm{p}$ $<0.07$ ) follow-up visits was the difference not statistically significantly different. When applying the alternate 5-item success criteria, the success rate was also significantly greater for the TDR group at all points but the 3-year follow-up ( $<<0.05$; Fig. 1 lower).

\section{Patient-Completed Questionnaires}

The mean NDI scores improved significantly in both treatment groups at the 6-week follow-up visit and remained significantly improved throughout the 5-year follow-up (both $\mathrm{p}<0.01$; Fig. 2). The mean values at 60 months were near identical to the 24-month values in both groups. Similar to the NDI scores, the mean VAS pain scores improved significantly by 6 weeks after surgery in

TABLE 2. Comparison of device- or surgery-related adverse events in the TDR and ACDF groups

\begin{tabular}{lcc}
\hline \multirow{2}{*}{ Category } & \multicolumn{2}{c}{ No. (\%) } \\
\cline { 2 - 3 } \multicolumn{1}{c}{ TDR } & ACDF \\
\hline No device- or surgery-related AE & $75(55.1 \%)$ & $80(60.2 \%)$ \\
\hline Definitely device related & $10(7.4 \%)$ & $8(6.0 \%)$ \\
\hline Probably device related & $4(3.0 \%)$ & $2(1.5 \%)$ \\
\hline Possibly device related & $38(27.9 \%)$ & $37(27.8 \%)$ \\
\hline Definitely procedure related & $2(1.5 \%)$ & $0(0.0 \%)$ \\
\hline Possibly procedure related & $6(4.4 \%)$ & $6(4.5 \%)$ \\
\hline AE = adverse event. & &
\end{tabular}

both groups and remained improved throughout the 5-year follow-up (both $\mathrm{p}<0.01$; Fig. 3).

\section{Adverse Events, Reoperations, and Revisions}

The percentage of patients with device- or surgery-related adverse events was similar in the 2 treatment groups (Table 2). Approximately $8 \%$ of both groups underwent reoperation or revision surgery (Table 3 ). There were no differences in the device relationship categories in comparing TDR with ACDF.

\section{Radiographic Assessment}

As seen in Fig. 4, ROM at the level implanted with the TDR decreased at 3 months after surgery, then increased by 6 months. The mean ROM at the 60 -month follow-up was significantly greater than the preoperative mean $(\mathrm{p}<$ 0.01 ). Device migration occurred in $1.4 \%$ of the TDR patients, as did subsidence. There were no cases of migration or subsidence in the ACDF group. In all patients in both groups, disc space height was maintained or improved at the 60-month follow-up compared with the preoperative

TABLE 3. Rates of reoperation/revision surgery in the TDR and ACDF groups

\begin{tabular}{lcc}
\hline \multirow{2}{*}{ Classification } & \multicolumn{2}{c}{ No. (\%) } \\
\cline { 2 - 3 } TDR & ACDF \\
\hline No reop or revision & $124(91.2 \%)$ & $122(91.7 \%)$ \\
\hline Definitely device related & $7(5.1 \%)$ & $6(4.5 \%)$ \\
\hline Probably device related & $4(3.0 \%)$ & $3(2.3 \%)$ \\
\hline Possibly device related & $0(0.0 \%)$ & $2(1.5 \%)$ \\
\hline
\end{tabular}




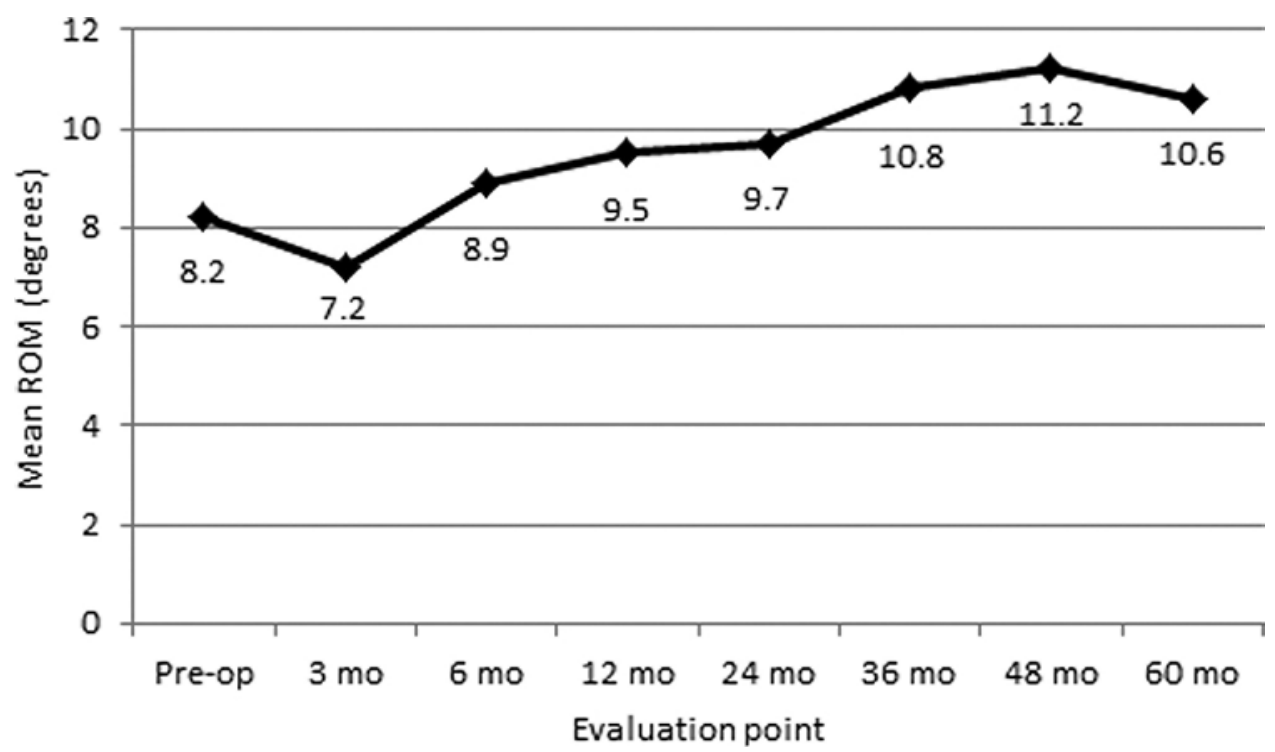

FIG. 4. The mean ROM in the TDR group decreased slightly at the 3-month follow-up, then increased to above the preoperative mean value, significantly so at the 60 -month follow-up ( $p<0.01$, paired t-test).

status. Radiolucency was noted at $14.3 \%$ of TDR implants and $7.0 \%$ of ACDF implants ( $p>0.20$ ). At 60 months, $89.5 \%$ of the ACDF group was classified as fused. There was some shifting in the percentage of patients in the $\mathrm{HO}$ categories when comparing preoperative scores to the 60-month scores (Fig. 5). At the 60-month follow-up, HO classified as bridging across the disc space was noted in $2.9 \%$ of the TDR group.

The ASD scores were similar preoperatively in the 2 groups. At 60 months after surgery, the TDR group had statistically significantly less ASD degeneration at the level superior to the index surgery than the ACDF group ( $\mathrm{p}<$ 0.01 ; Fig. 6). The TDR group had less ASD degeneration at the inferior level but not significantly less than that in the ACDF group ( $p>0.25)$.

\section{Serum Ion Analysis}

In the metal ion substudy, data through the extended follow-up of the metal ion cohort showed low and stable serum metal ion levels. From 3 to 60 months postoperatively, mean cobalt levels steadily decreased whereas mean chromium levels remained stable, slightly decreasing throughout the follow-up period. At 60 months, the subjects' mean serum cobalt and chromium levels were low: 0.21 and $0.31 \mu \mathrm{g} / \mathrm{L}$, respectively (Fig. 7). As seen in the figure, the cobalt and chromium values in the current

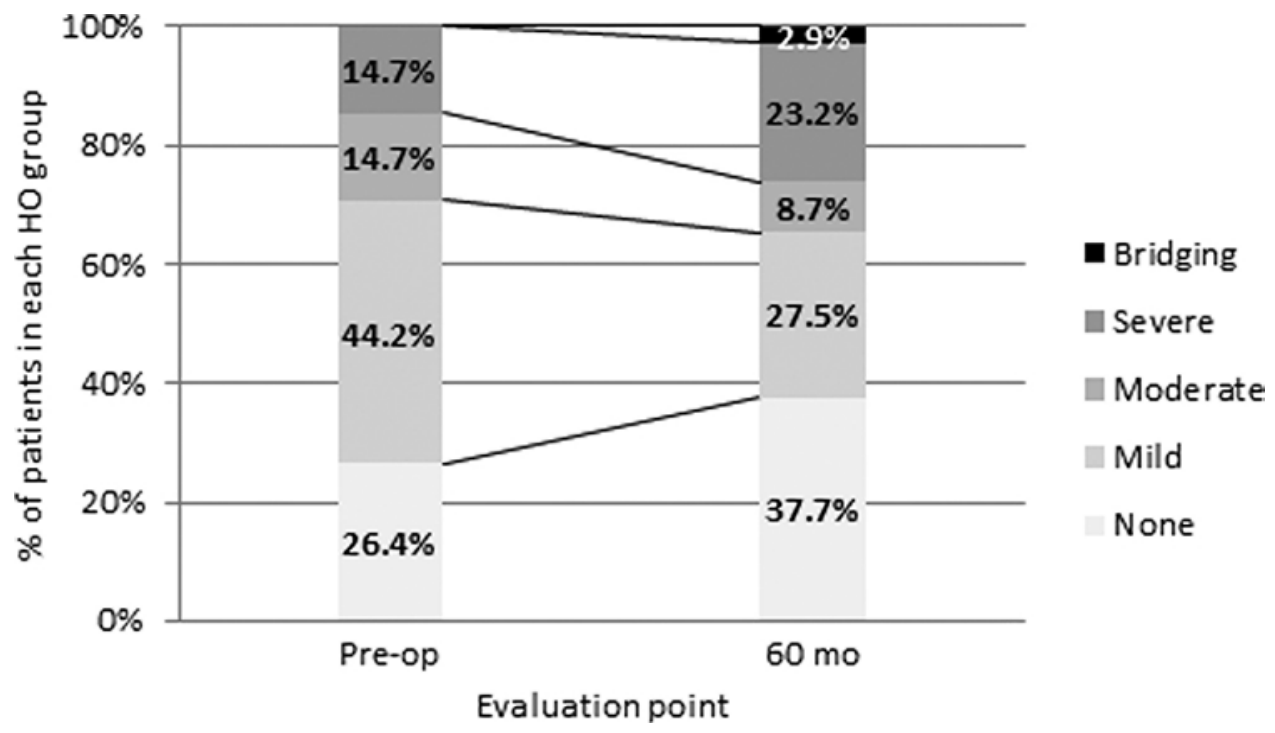

FIG. 5. Percentage of patients in the $\mathrm{HO}$ categories preoperatively and at 60 months postoperatively. 


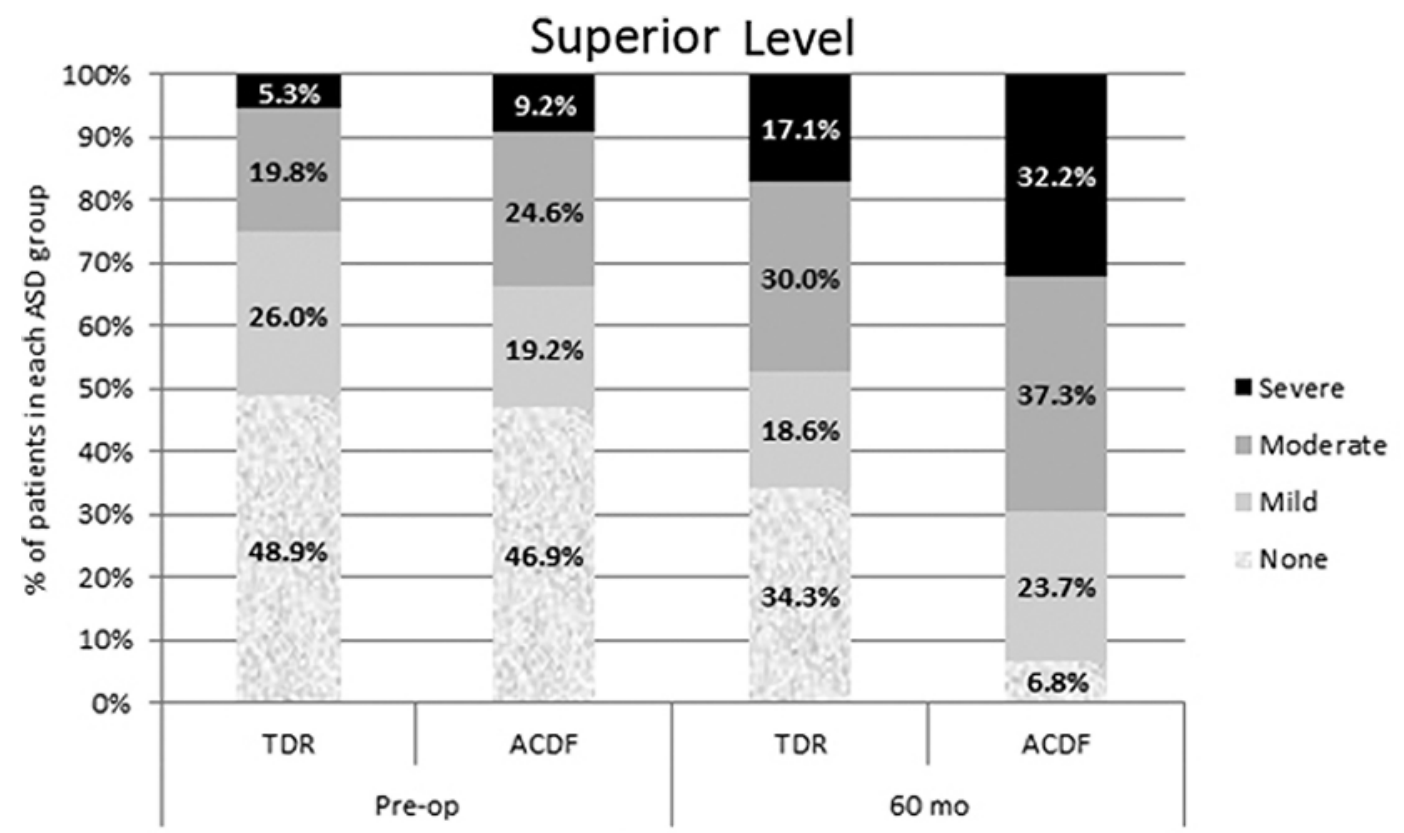

Evaluation point

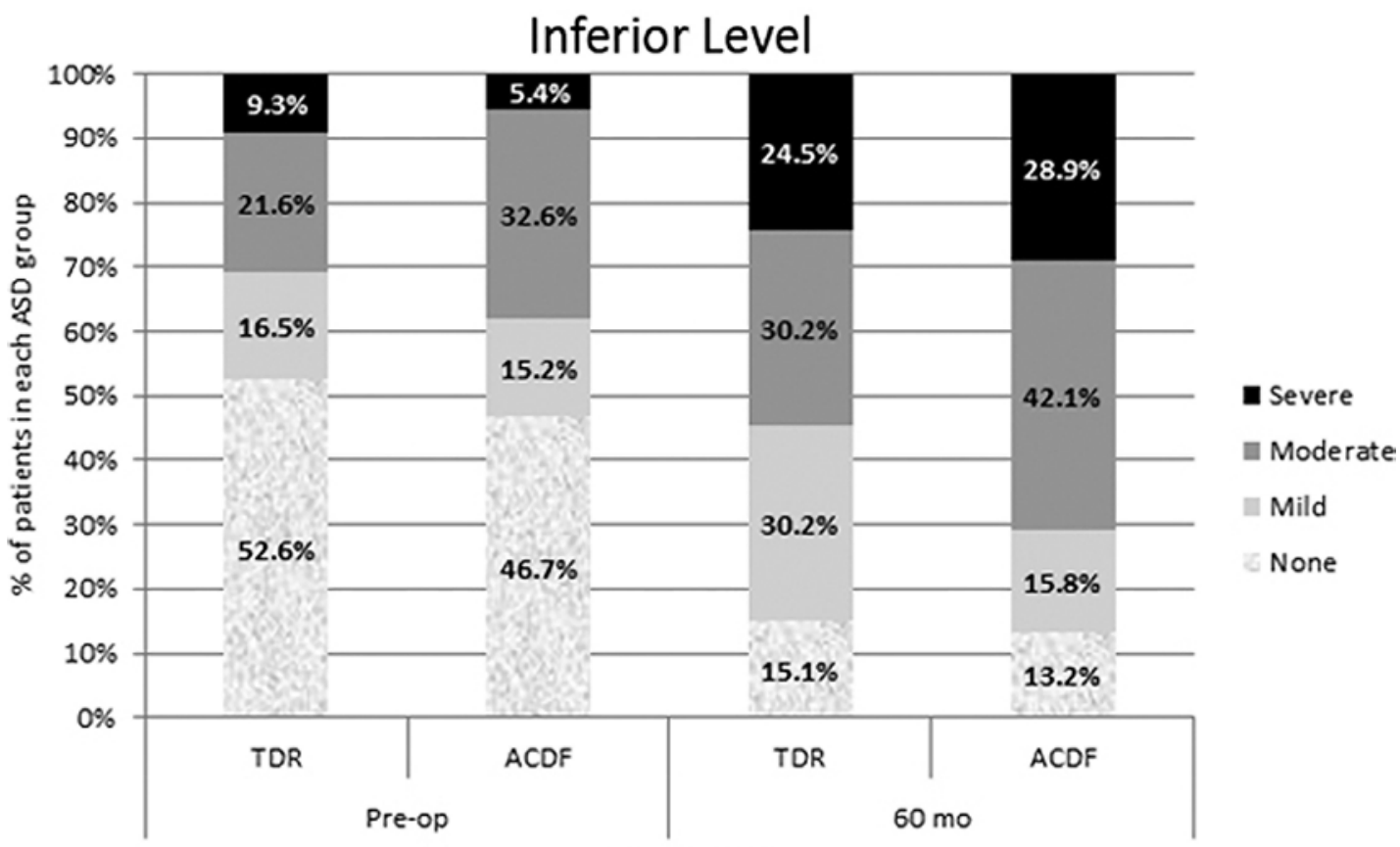

Evaluation point

FIG. 6. Preoperatively, the proportional distribution of ASD was similar in the TDR and ACDF groups. At the 5-year follow-up, ASD was significantly worse at the superior level in the fusion group ( $p<0.01$, upper) and worse at the inferior level but not significantly so (lower).

study were much lower than those suggested to warrant ongoing monitoring of hip replacement patients. ${ }^{19,29}$

\section{Discussion}

This study showed that the results noted at the 2-year follow-up were maintained through the 5-year follow-up period according to a composite success score, pain and function questionnaires, and radiographic assessments. As expected, the percentage of patients lost to follow-up increased by the 60 -month follow-up (TDR $=31.6 \%$; ACDF $=37.6 \%$ ), which may introduce the potential for selection bias. Follow-up rates are similar to those of another published TDR IDE study at the 5-year follow-up. ${ }^{23}$ The TDR group in our study had outcomes similar or superior to those of the ACDF group on all outcome measures 


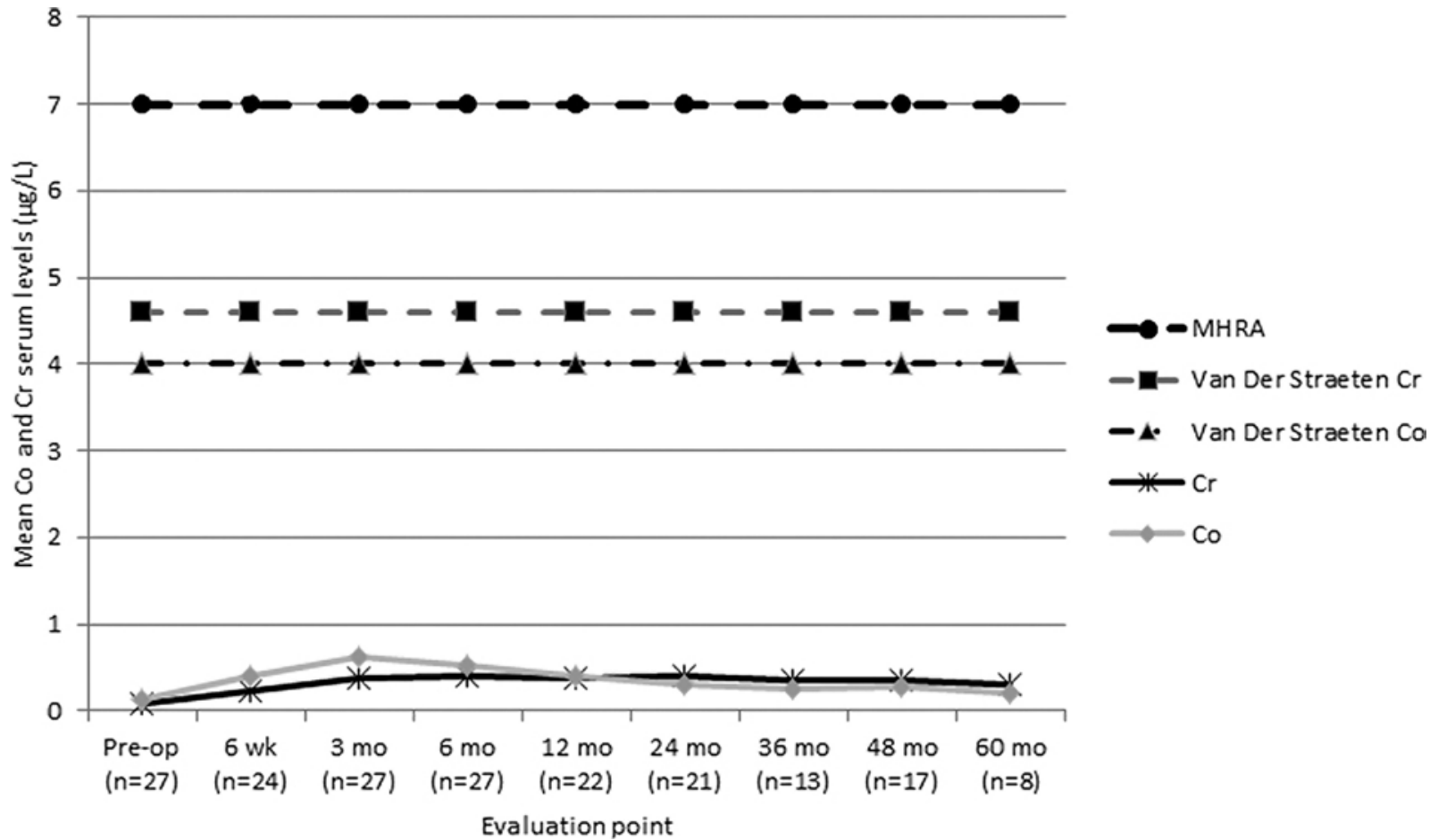

FIG. 7. The cobalt (Co) and chromium ( $\mathrm{Cr}$ ) levels identified by the serum ion testing in the current study were well below levels recommended to initiate monitoring of patients following hip replacement. MHRA = Medicines and Healthcare products Regulatory Agency; Van Der Straeten = Van Der Straeten et al., 2013.

throughout the 5-year follow-up. The difference in the primary composite overall success scores was statistically significant in favor of TDR at the 24- and 60-month follow-ups, but not at the 36- and 48-month follow-ups. The primary self-reported patient indices for disability (NDI) and pain (VAS) were significantly improved in both groups by the 3-month follow-up and were maintained through the 60-month follow-up, but there were no statistically significant differences between groups. Given the lack of a statistically significant difference between the groups on validated outcome measures, the observed difference in overall composite success between the groups may be affected by patients in the ACDF group with asymptomatic pseudarthrosis. However, this would not account for the slight decline in the success rate in the ACDF group during the later follow-up periods. The results support the clinical efficacy of both treatments as well as the noninferiority of MoM TDR compared with ACDF during the long-term follow-up. These findings are similar to those reported for other cervical TDR devices throughout a 5-year follow-up. ${ }^{1,12,31}$

Continued motion of the TDR throughout the 5-year follow-up is supported by the finding that the mean ROM value was greater than the preoperative value. The percentage of patients with $\mathrm{HO}$ increased over time. However, at the 5-year follow-up, only $2.9 \%$ of the TDR patients had HO severe enough to result in bone bridging across the disc space, eliminating movement. The rate of bridging $\mathrm{HO}$ was less than reported in another study with a 5-year follow-up. ${ }^{12}$ It was recently reported that higher levels of
$\mathrm{HO}$ were related to greatly increasing the disc space height and ROM of the operated segment. ${ }^{15}$ The ROM in the high $\mathrm{HO}$ group was increased by a mean of $6.7^{\circ}$ versus $3.1^{\circ}$ in the low-grade HO group. In the current study, the mean increase in ROM did not exceed $3^{\circ}$ at any follow-up point. In cervical TDR patients, it appears that $\mathrm{HO}$ formation is a multifactorial process including such factors as surgical technique (for example, use of high-speed drill, devitalization of surrounding tissues, exposure of cancellous bone), type and size of device used (that is, unconstrained vs semi-constrained), and natural history of degenerative changes, including osteophytes, in a population treated for pain related to degenerative changes.

The radiographic ASD rates were similar in the TDR and ACDF groups prior to surgery. At 60 months, the TDR group had significantly less ASD at the level superior to the operated level than did the ACDF patients. This was noted at the 2-year follow-up as well in this study group. ${ }^{3}$ These results support the existing literature indicating that TDR is associated with less ASD than fusion. ${ }^{12,27}$ There was no significant difference in the overall rate of adjacent level surgery between groups.

One concern with the MoM TDR designs has been the potential for problems related to wear debris. This concern has primarily stemmed from reports of wear debris associated with MoM hip prostheses ${ }^{5,17}$ as well as several cases reporting reactions to MoM TDRs. ${ }^{2,9,14,16}$ In response to the controversy generated from wear debris related to MoM hip implants, the Medicines and Healthcare products Regulatory Agency released a device alert issuing 
threshold serum values for cobalt and chromium at which hip replacement patients merit ongoing monitoring. Recently, Van Der Straeten et al. evaluated cobalt and chromium levels related to a reduced clinical outcome following hip replacement surgery. ${ }^{29}$ The highest values found in the current study were less than $25 \%$ of the threshold values suggested in either of these works. Our study is the first to report the long-term results for a cobalt-chromium MoM cervical TDR device. The serum ion levels in our study were lower than those noted for a lumbar MoM TDR of similar design, ${ }^{8}$ another MoM TDR,${ }^{6}$ and, most importantly, well below the threshold levels suggested by the Medicines and Healthcare products Regulatory Agency to trigger monitoring of MoM hip replacement patients..$^{19,29}$ Total disc replacements and hip replacements are designed for very different applications and differ greatly in size, amount of motion, and loading and can therefore be expected to have different potentials for producing amounts of clinically relevant wear. A cervical TDR is much smaller with less concomitant load. In comparing the wear of MoM TDRs with core diameters ranging from 10 to 16 $\mathrm{mm}$, it was found that the smaller diameters were associated with less wear. ${ }^{20}$ In the present series, 2 patients underwent reoperation for removal of the TDR related to a lymphocytic reaction to the implant, as has been described in detail in the literature. ${ }^{9,14}$ While infrequent, surgeons should be aware of the possible reaction to MoM TDRs. These reactions include pseudotumor formation or osteolysis with implant loosening or migration. The optimal treatment for such metal reactions is removal of the TDR followed by fusion. , $^{, 14}$

\section{Conclusions}

Results of this prospective randomized study showed that at the 5-year follow-up TDR and ACDF produced significant pain relief and improved quality of life as early as 6 weeks after surgery and that the improvement was maintained for the 5-year follow-up. There were statistically significant differences between the groups, favoring TDR when evaluating ASD and some clinical outcome measures. At no point was there a significant difference favoring ACDF. The TDR group maintained the mean ROM from the preoperative value and had a small percentage of patients developing bridging $\mathrm{HO}$. These results add to the existing body of literature supporting cervical TDR as a viable alternative to ACDF for the treatment of single-level radiculopathy and indicate that the MoM cervical arthroplasty design is safe.

\section{Appendix \\ Kineflex|C Investigators and Sites}

Jeffrey Roh, MD, Orthopedics International Spine, Seattle, Washington; Thomas A. Dimming, MD, Triangle Orthopedic Associates, P.A., Independence Park, Durham, North Carolina; Jeffrey Donner, MD, Rocky Mountain Associates in Orthopedic Medicine, PC, Loveland, Colorado; James Rappaport, MD, Sierra Regional Spine Institute, Reno, Nevada; Carl Lauryssen, MD, Tower Orthopedics and Sports Medicine, Beverly Hills, California; Domagoj Coric, MD, Carolina Neurosurgery and Spine Associates, PA, Charlotte, North Carolina; Peter Gertszten, MD, MPH, University of Pittsburgh Medical Center, Pittsburgh, Pennsylvania;
Kevin T. Foley, MD, Semmes Murphey Clinic, Memphis, Tennessee; John Rhee, MD, Emory Orthopedics \& Spine Center, Atlanta, Georgia; Cameron Carmody, MD, Plano Orthopedic Sports Medicine \& Spine, Plano, Texas; Paul C. McAfee, MD, Towson Orthopedic Associates, P.A., Towson, Maryland; Richard D. Guyer, MD, SpineMark Clinical Research Organization at TBI, L.P., Plano, Texas; Ravinder Bains, MD, Kaiser Oakland Regional Spine Surgery Hospital, Oakland, California; William Taylor, MD, University of California San Diego, La Jolla, California; Pierce Nunley, MD, Spine Institute of Louisiana, Shreveport, Louisiana; Fabien D. Bitan, MD, Manhattan Orthopedic, P.C., New York, New York; Gary Dix, MD, Maryland Brain and Spine Center, Annapolis, Maryland; Charley Gordon, MD, Gordon Spine Associates, Tyler, Texas; John Abrahams, MD, Northern Westchester Hospital, Mount Kisco, New York; Harry Herkowitz, MD, William Beaumont Hospital, Royal Oak, Michigan; and Andrew Cappuccino, MD, Buffalo Spine Surgery, Lockport, New York.

\section{Dates of the Study}

First patient enrolled 7/19/2005; study terminated 8/21/2013.

\section{References}

1. Aghayev E, Bärlocher C, Sgier F, Hasdemir M, Steinsiepe KF, Wernli F, et al: Five-year results of cervical disc prostheses in the SWISSspine registry. Eur Spine J 22:1723-1730, 2013

2. Cavanaugh DA, Nunley PD, Kerr EJ III, Werner DJ, Jawahar A: Delayed hyper-reactivity to metal ions after cervical disc arthroplasty: a case report and literature review. Spine (Phila Pa 1976) 34:E262-E265, 2009

3. Coric D, Nunley PD, Guyer RD, Musante D, Carmody CN, Gordon CR, et al: Prospective, randomized, multicenter study of cervical arthroplasty: 269 patients from the KineflexlC artificial disc investigational device exemption study with a minimum 2-year follow-up: clinical article. J Neurosurg Spine 15:348-358, 2011

4. Davis RJ, Nunley PD, Kim KD, Hisey MS, Jackson RJ, Bae $\mathrm{HW}$, et al: Two-level total disc replacement with Mobi-C cervical artificial disc versus anterior discectomy and fusion: a prospective, randomized, controlled multicenter clinical trial with 4-year follow-up results. J Neurosurg Spine 22:15-25, 2015

5. Garbuz DS, Tanzer M, Greidanus NV, Masri BA, Duncan CP: Metal-on-metal hip resurfacing versus large-diameter head metal-on-metal total hip arthroplasty: a randomized clinical trial. Clin Orthop Relat Res 468:318-325, 2010

6. Gornet MF, Burkus JK, Harper ML, Chan FW, Skipor AK, Jacobs JJ: Prospective study on serum metal levels in patients with metal-on-metal lumbar disc arthroplasty. Eur Spine J 22:741-746, 2013

7. Gornet MF, Burkus JK, Shaffrey ME, Argires PJ, Nian H, Harrell FE Jr: Cervical disc arthroplasty with PRESTIGE LP disc versus anterior cervical discectomy and fusion: a prospective, multicenter investigational device exemption study. J Neurosurg Spine 23:558-573, 2015

8. Guyer RD, Pettine K, Roh JS, Dimmig TA, Coric D, McAfee PC, et al: Five-year follow-up of a prospective, randomized trial comparing two lumbar total disc replacements. Spine (Phila Pa 1976) 41:3-8, 2016

9. Guyer RD, Shellock J, MacLennan B, Hanscom D, Knight $\mathrm{RQ}$, McCombe P, et al: Early failure of metal-on-metal artificial disc prostheses associated with lymphocytic reaction: diagnosis and treatment experience in four cases. Spine (Phila Pa 1976) 36:E492-E497, 2011

10. Heller JG, Sasso RC, Papadopoulos SM, Anderson PA, Fessler RG, Hacker RJ, et al: Comparison of BRYAN cervical disc arthroplasty with anterior cervical decompression and fusion: clinical and radiographic results of a randomized, controlled, clinical trial. Spine (Phila Pa 1976) 34:101-107, 2009 
11. Hisey MS, Bae HW, Davis R, Gaede S, Hoffman G, Kim K, et al: Multi-center, prospective, randomized, controlled investigational device exemption clinical trial comparing Mobi-C Cervical Artificial Disc to anterior discectomy and fusion in the treatment of symptomatic degenerative disc disease in the cervical spine. Int J Spine Surg 8:7, 2014

12. Hisey MS, Zigler JE, Jackson R, Nunley PD, Bae HW, Kim $\mathrm{KD}$, et al: Prospective, randomized comparison of one-level Mobi-C Cervical Total Disc Replacement vs. anterior cervical discectomy and fusion: results at 5-year follow-up. Int J Spine Surg 10:10, 2016

13. Kang DG, Wagner SC, Lehman RA Jr: Osteolysis in the setting of metal-on-metal cervical disc arthroplasty. Spine J 14:1362-1365, 2014

14. Karnoub MA, Zairi F, Aboukais R, Assaker R: Delayed hypersensitivity reaction: an increasingly recognized complication of metal-on-metal total disc replacement. Case Rep Orthop 2015:416548, 2015

15. Kim KS, Heo DH: Do postoperative biomechanical changes induce heterotopic ossification after cervical arthroplasty?: A 5-year follow-up study. Clin Spine Surg 29:E309-E313, 2016

16. Lagier M, Briere M, Giorgi H, Fuentes S, Blondel B, Tropiano P: Delayed hypersensitivity reaction after cervical disc replacement: a case report. Orthop Traumatol Surg Res 101:643-645, 2015

17. MacDonald SJ, McCalden RW, Chess DG, Bourne RB, Rorabeck CH, Cleland D, et al: Metal-on-metal versus polyethylene in hip arthroplasty: a randomized clinical trial. Clin Orthop Relat Res (406):282-296, 2003

18. McAfee PC, Cunningham BW, Devine J, Williams E, Yu-Yahiro J: Classification of heterotopic ossification (HO) in artificial disk replacement. J Spinal Disord Tech 16:384-389, 2003

19. Medicines and Healthcare Products Regulatory Agency: Medical device alert: All metal-on-metal (MoM) hip replacements. (http://webarchive.nationalarchives.gov. uk/20130513184637/http://www.mhra.gov.uk/home/groups/ dts-bs/documents/medicaldevicealert/con079162.pdf) [Accessed September 19, 2017]

20. Moghadas P, Mahomed A, Hukins DW, Shepherd DE: Friction in metal-on-metal total disc arthroplasty: effect of ball radius. J Biomech 45:504-509, 2012

21. Mummaneni PV, Burkus JK, Haid RW, Traynelis VC, Zdeblick TA: Clinical and radiographic analysis of cervical disc arthroplasty compared with allograft fusion: a randomized controlled clinical trial. J Neurosurg Spine 6:198-209, 2007

22. Murrey D, Janssen M, Delamarter R, Goldstein J, Zigler J, Tay B, et al: Results of the prospective, randomized, controlled multicenter Food and Drug Administration investigational device exemption study of the ProDisc-C total disc replacement versus anterior discectomy and fusion for the treatment of 1-level symptomatic cervical disc disease. Spine J 9:275-286, 2009

23. Phillips FM, Geisler FH, Gilder KM, Reah C, Howell KM, McAfee PC: Long-term outcomes of the US FDA IDE prospective, randomized controlled clinical trial comparing PCM cervical disc arthroplasty with anterior cervical discectomy and fusion. Spine (Phila Pa 1976) 40:674-683, 2015

24. Phillips FM, Lee JY, Geisler FH, Cappuccino A, Chaput CD, DeVine JG, et al: A prospective, randomized, controlled clinical investigation comparing PCM cervical disc arthroplasty with anterior cervical discectomy and fusion. 2-year results from the US FDA IDE clinical trial. Spine (Phila Pa 1976) 38:E907-E918, 2013

25. Radcliff K, Coric D, Albert T: Five-year clinical results of cervical total disc replacement compared with anterior discectomy and fusion for treatment of 2-level symptomatic degenerative disc disease: a prospective, randomized, con- trolled, multicenter investigational device exemption clinical trial. J Neurosurg Spine 25:213-224, 2016

26. Staub LP, Ryser C, Röder C, Mannion AF, Jarvik JG, Aebi $\mathrm{M}$, et al: Total disc arthroplasty versus anterior cervical interbody fusion: use of the Spine Tango registry to supplement the evidence from randomized control trials. Spine J 16:136-145, 2016

27. Tian W, Yan K, Han X, Yu J, Jin P, Han X: Comparison of the clinical and radiographic results between cervical artificial disc replacement and anterior cervical fusion: a 6-year prospective nonrandomized comparative study. Clin Spine Surg 30:E578-E586, 2017

28. Vaccaro A, Beutler W, Peppelman W, Marzluff JM, Highsmith J, Mugglin A, et al: Clinical outcomes with selectively constrained SECURE-C cervical disc arthroplasty: two-year results from a prospective, randomized, controlled, multicenter investigational device exemption study. Spine (Phila Pa 1976) 38:2227-2239, 2013

29. Van Der Straeten C, Grammatopoulos G, Gill HS, Calistri A, Campbell P, De Smet KA: The interpretation of metal ion levels in unilateral and bilateral hip resurfacing. Clin Orthop Relat Res 471:377-385, 2013

30. Zhang X, Zhang X, Chen C, Zhang Y, Wang Z, Wang B, et al: Randomized, controlled, multicenter, clinical trial comparing BRYAN cervical disc arthroplasty with anterior cervical decompression and fusion in China. Spine (Phila Pa 1976) 37:433-438, 2012

31. Zigler JE, Delamarter R, Murrey D, Spivak J, Janssen M: ProDisc-C and anterior cervical discectomy and fusion as surgical treatment for single-level cervical symptomatic degenerative disc disease: five-year results of a Food and Drug Administration study. Spine (Phila Pa 1976) 38:203-209, 2013

\section{Disclosures}

SpinalMotion Inc. was responsible for the design and conduct of this multicenter, prospective, randomized FDA-regulated IDE pivotal trial (IDE No. G050035) and provided clinical research support for it to the participating clinical sites. SpinalMotion Inc. provided statistical analysis for the study but did not provide any writing assistance for this paper. SpinalMotion is no longer an incorporated company.

The authors report the following. Drs. Coric, Guyer, and Lauryssen: consultants for and direct stock ownership in SpinalMotion. Dr. Nunley: consultant for SpinalMotion; consultant for Vertiflex, LDR Spine/Zimmer-Biomet, and K2M; patent holder with LDR Spine/Zimmer-Biomet and K2M; direct stock ownership in Amedica, Safewire, Paradigm, and Spineology; and received support from Vertiflex, LDR Spine/Zimmer-Biomet, and K2M for non-study-related clinical or research effort overseen by him. Dr. Coric: received clinical or research support for the study described in this paper; Spine Wave-consultant, stock ownership, royalties; Stryker Spine-consultant, royalties; Globus Medical-consultant; Medtronic-consultant; RTI Surgical-royalties; Spinal Kinetics-stock; Premia Spine-consultant, stock; Integrity Implants-consultant; and United HealthCare-Spine Advisory Board.

\section{Author Contributions}

Acquisition of data: Coric, Guyer, Musante, Carmody, Gordon, Lauryssen, Boltes. Analysis and interpretation of data: Ohnmeiss. Drafting the article: Ohnmeiss. Critically revising the article: Coric, Guyer. Reviewed submitted version of manuscript: Musante, Carmody, Gordon, Lauryssen, Boltes.

\section{Correspondence}

Dom Coric: Carolina Neurosurgery \& Spine Associates, Charlotte, NC.dom@cnsa.com. 